\title{
Perbandingan Luaran Maternal dan Neonatal antara Seksio Cesarea Emergensi dan Seksio Cesarea Elektif pada Kehamilan dengan Janin Presentasi Bokong
}

\author{
Riena Reubiyana ${ }^{1}$, Ahsanudin Attamimi², Eugenius Phyowai Ganap ${ }^{3}$ \\ 1,2,3 Departemen Obstetri dan Ginekologi, Fakultas Kedokteran, Kesehatan Masyarakat, dan Keperawatan \\ Universitas Gadjah Mada \\ Korespondensi: reubiyana@mail.ugm.ac.id
}

Submisi: 15 Januari 2021; Revisi: 18 Januari 2021; Penerimaan: 22 Januari 2021

\begin{abstract}
Background: Breech presentation occurred at $3-4 \%$ of all single births. Recently, the breech presentation is $\pm 17 \%$ of the indication to perform elective caesarean section. Caesarean section can be a life-saving procedure to mother and baby, but also can cause adverse maternal and neonatal complications. Elective caesarean section is known to be associated with a lower risk of maternal and neonatal complications than emergency caesarean section.

Objective: This study aims to compare maternal and neonatal outcome of breech presentation patients that underwent emergency or elective caesarean section.

Method: A retrospective cohort design study was conducted with consecutive sampling methods of pregnant women with breech presentation who underwent emergency and elective caesarean section during 2014-2019. Two groups of delivery methods were compared. Outcomes of the study were maternal outcome that were infection and hemorrhage, while the neonatal outcomes were birth asphyxia and birth trauma. Data was analyzed using the Chi Square test or Fisher's Exact test and multivariate using logistic regression test.

Results and Discussion: Total sample was 240 subjects, consisting of 105 samples in emergency caesarean section and 135 sample in elective caesarean section. From bivariate analysis, incidence of low Apgar score at first minute and fifth minute and also birth trauma in emergency caesarean section group were higher than elective caesarean section, but not statistically significant. From multivariate analysis, emergency caesarean section correlated with greater number of the complications risk incidence that were maternal infection ( $p=0.002$, OR $3.65,95 \% \mathrm{Cl} 1.59-8.40)$, hemorrhage ( $p=0.042$, OR 2.27, 95\% Cl 1.06-6.1).

Conclusion: Emergency caesarean section significantly correlated with the incidence of the adverse maternal that are infection and maternal hemorrhage, but had no difference in neonatal outcome between emergency and elective caesarean section. Antenatal care examination and precise management in making termination decision are required to avoid complications.
\end{abstract}

Keywords: breech presentation; emergency caesarean section; elective caesarean section; maternal outcome; neonatal outcome.

\begin{abstract}
ABSTRAK
Latar Belakang: Kehamilan dengan janin presentasi bokong terjadi pada 3-4\% dari semua kelahiran tunggal. Presentasi bokong merupakan $\pm 17 \%$ indikasi utama dikerjakannya seksio cesarea elektif saat ini. Seksio cesarea dapat menjadi prosedur untuk menyelamatkan ibu dan bayi, tetapi juga dapat menyebabkan komplikasi untuk ibu dan bayi. Seksio cesarea elektif diyakini dapat menurunkan risiko terjadinya komplikasi maternal dan neonatal dibandingkan seksio cesarea emergensi.

Tujuan: Penelitian ini bertujuan untuk menilai luaran maternal dan neonatal antara seksio cesarea emergensi dan elektif dengan mengambil sampel pada kehamilan dengan janin presentasi bokong.

Metode: Penelitian dilakukan dengan desain kohort retrospektif. Pengambilan sampel dilakukan secara konsekutif pada subjek ibu hamil dengan janin presentasi bokong yang melahirkan secara seksio cesarea selama tahun 2014-2019. Dua kelompok yang dibandingkan yaitu seksio cesarea emergensi dan elektif. Luaran penelitian adalah luaran maternal berupa kejadian infeksi dan perdarahan, sedangkan luaran neonatal adalah asfiksia dan cedera neonatal. Data dianalisis dengan uji Chi Square atau Fisher Exact, dilanjutkan uji regresi logistik.

Hasil dan Pembahasan: Terdapat 240 sampel, terdiri dari 105 sampel seksio cesarea emergensi dan 135 sampel seksio cesarea elektif. Dari hasil analisis bivariat, diperoleh bahwa seksio cesarea emergensi berhubungan dengan lebih tingginya kejadian nilai Apgar rendah pada menit pertama dan menit kelima dan cedera persalinan, meskipun tidak bermakna secara statistik. Analisis multivariat menunjukkan bahwa seksio cesarea emergensi berhubungan dengan terjadinya infeksi maternal $(p=0.002$, OR 3.65, 95\% $\mathrm{Cl} 1.59-8.40)$ dan perdarahan ( $\mathrm{p}=0.042, \mathrm{OR} 2.27,95 \% \mathrm{Cl} 1.06-6.1)$.

Kesimpulan: Seksio cesarea emergensi secara signifikan berhubungan dengan luaran buruk maternal, yaitu terjadinya komplikasi infeksi dan perdarahan, namun tidak memberikan luaran neonatal yang lebih buruk dibandingkan seksio cesarea elektif. Pemeriksaan antenatal dan pengambilan keputusan penatalaksanaan yang tepat diperlukan untuk menekan terjadinya komplikasi.
\end{abstract}

Kata kunci: kehamilan dengan presentasi bokong; seksio cesarea emergensi; seksio cesarea elektif; luaran maternal; luaran neonatal. 


\section{PENDAHULUAN}

Metode persalinan termasuk hal yang menentukan luaran bayi yang dilahirkan. Meskipun berisiko, angka kejadian seksio cesarea terus meningkat di banyak negara termasuk Indonesia. Seksio cesarea memiliki risiko tinggi tidak hanya bagi sang ibu tapi juga bagi janin. ${ }^{1}$ Kehamilan dengan janin presentasi bokong terjadi pada $40 \%$ pada kehamilan 20 minggu, 6-8\% pada kehamilan 34 minggu dan $2-3 \%$ kehamilan aterm. ${ }^{2}$ Belum ada konsensus yang konklusif untuk penentuan metode persalinan yang terbaik pada presentasi bokong. Hampir sebagian penelitian mengatakan bahwa seksio cesarea elektif dapat menurunkan mortalitas dan morbiditas pada neonatal dibandingkan persalinan vaginal. ${ }^{3}$ Namun demikian, persalinan vaginal masih menjadi pilihan yang aman dengan ketentuan manajemen yang ketat, kriteria seleksi pasien yang cermat dan persalinan dengan tenaga ahli obstetri yang berpengalaman. ${ }^{4,5}$ Namun, selama percobaan persalinan vaginal, ada kasus-kasus pasien yang gagal dilakukan persalinan vaginal sehingga harus berakhir dengan dilakukannya seksio cesarea emergensi.

Walaupun seksio cesarea memberikan luaran bayi yang lebih baik, namun juga dapat menyebabkan terjadinya komplikasi jangka pendek dan jangka panjang untuk ibu dan bayi. Komplikasi jangka pendek pada ibu dapat berupa perdarahan, cedera organ sekitar, endometritis, infeksi, thromboembolism dan komplikasi jangka panjang dapat terjadi kelainan letak plasenta dan kemungkinan kejadian operasi seksio cesarea pada kehamilan berikutnya. ${ }^{6,7}$ Pada neonatal, morbiditas seksio cesarea, diantaranya adalah asfiksia, komplikasi luka iris pada bayi, dan fraktur ekstremitas bayi. ${ }^{8}$ Seksio cesarea emergensi, dengan indikasi obstetri apapun, diyakini memiliki angka kejadian komplikasi maternal dan neonatal lebih tinggi daripada seksio cesarea elektif. ${ }^{7,9}$ Penelitian ini bertujuan untuk membandingkan luaran maternal dan neonatal antara persalinan seksio cesarea emergensi dan elektif dengan mengambil sampel kehamilan dengan janin presentasi bokong.

\section{METODE}

Penelitian ini merupakan penelitian kohort retrospektif yang akan membandingkan luaran maternal dan neonatal antara seksio cesarea emergensi dan elektif pada kehamilan dengan janin presentasi bokong. Penelitian dilakukan di RSUP dr. Sardjito, RSUD Sleman, dan RSUD Panembahan Senopati Bantul, Propinsi Daerah Istimewa Yogyakarta. Penelitian dilakukan dengan mengambil data sekunder dari rekam medis ibu dan bayi. Populasi dalam penelitian adalah semua ibu hamil dengan janin presentasi bokong yang melahirkan secara seksio cesarea pada bulan Januari 2014 hingga Desember 2019. Sampel penelitian adalah pasien yang memenuhi kriteria inklusi dan eksklusi. Kriteria inklusi meliputi: 1) ibu hamil dengan janin tunggal, presentasi bokong, yang melahirkan secara seksio cesarea, 2) terminasi kehamilan dilakukan pada usia kehamilan $\geq 34$ minggu $-\leq 42$ minggu, 3) memiliki data rekam medis ibu dan bayi yang lengkap. Kriteria eksklusi dari penelitian ini adalah: 1) ibu hamil dengan janin yang memiliki kelainan kongenital, 2) ibu hamil dengan janin mati.

Luaran yang dinilai dalam penelitian ini adalah luaran maternal berupa infeksi pasca operasi dan perdarahan, sedangkan luaran neonatal yaitu asfiksia dan cedera persalinan. Infeksi diambil dari informasi mengenai adanya demam, luka basah, luka dengan pus, terjadinya dehisensi, adanya penyakit infeksi lain yang tidak ditemukan sebelum seksio cesarea. Luaran perdarahan dianalisis dari jumlah perdarahan $>1000 \mathrm{ml}$ setelah kala bayi lahir. Luaran neonatal untuk asfiksia dinilai dari skor Apgar menit pertama dan kelima, dan cedera akibat persalinan dinilai saat bayi lahir, ada tidaknya jejas, termasuk laserasi, perdarahan intracerebral, fraktur atau dislokasi.

Analisis univariat dilakukan untuk menggambarkan variabel yang berhubungan dengan seksio cesarea emergensi. Hubungan antara kelompok sekdio cesarea dengan setiap luaran maternal dan neonatal dianalisis secara bivariat. Derajat kemaknaan yang digunakan adalah nilai $p$, yaitu nilai $p$ kurang dari 0,05 dianggap bermakna signifikan. Analisis multivariat menggunakan regresi logistik biner dilakukan untuk menguji hubungan antara seksio cesarea dan luaran maternal neonatal dengan melibatkan variabel luar. Pengolahan data menggunakan SPSS 23.0. 


\section{HASIL DAN PEMBAHASAN}

Dari 1 Januari 2014 hingga 31 Desember 2019 didapatkan sebanyak 240 ibu hamil yang memenuhi kriteria inklusi dan eksklusi penelitian, terdiri dari
105 pasien yang melahirkan secara seksio cesarea emergensi dan 135 pasien yang melahirkan secara seksio cesarea elektif.

Tabel 1. Karakteristik dasar subjek penelitian

\begin{tabular}{|c|c|c|c|c|c|c|}
\hline & \multirow{3}{*}{ Variabel } & \multicolumn{4}{|c|}{ Persalinan } & \multirow{3}{*}{$p$} \\
\hline & & \multicolumn{2}{|c|}{ SC Emergensi } & \multicolumn{2}{|c|}{ SC Elektif } & \\
\hline & & $n$ & $\%$ & $n$ & $\%$ & \\
\hline \multirow[t]{2}{*}{ Usia ibu } & $<20$ atau $>35$ tahun & 31 & 29,5 & 36 & 26,7 & \multirow[t]{2}{*}{0,600} \\
\hline & 20-35 tahun & 74 & 70,5 & 99 & 73,3 & \\
\hline \multirow[t]{2}{*}{ Paritas } & Primigravida & 58 & 55,2 & 59 & 43,7 & \multirow[t]{2}{*}{0,068} \\
\hline & Multigravida & 47 & 44,8 & 76 & 56,3 & \\
\hline \multirow[t]{2}{*}{ Usia kehamilan } & $<37$ minggu & 32 & 30,5 & 28 & 20,8 & \multirow[t]{2}{*}{0,078} \\
\hline & $\geq 37$ minggu & 73 & 69,5 & 107 & 79,2 & \\
\hline \multirow[t]{2}{*}{ Berat bayi lahir } & $<2500$ atau $>3500$ gram & 52 & 49,5 & 46 & 34,1 & \multirow[t]{2}{*}{0,014} \\
\hline & 2500-3500 gram & 53 & 50,5 & 89 & 65,9 & \\
\hline \multirow[t]{2}{*}{ Hipertensi } & Ya & 30 & 28,6 & 29 & 21,5 & \multirow[t]{2}{*}{0,227} \\
\hline & Tidak & 75 & 71,4 & 106 & 78,5 & \\
\hline \multirow[t]{2}{*}{ Diabetes melitus } & Ya & 4 & 3,8 & 1 & 0,7 & \multirow[t]{2}{*}{0,170} \\
\hline & Tidak & 101 & 96,2 & 134 & 99,3 & \\
\hline \multirow{2}{*}{$\begin{array}{l}\text { Lama ketuban } \\
\text { pecah }\end{array}$} & $\geq 8$ jam & 25 & 23,8 & 3 & 2,2 & \multirow[t]{2}{*}{0,000} \\
\hline & $<8$ jam & 80 & 76,2 & 132 & 97,8 & \\
\hline
\end{tabular}

Indikasi seksio cesarea tertera dalam Tabel 2 dan 3. Indikasi seksio cesarea emergensi paling

Tabel 2. SC Emergensi

\begin{tabular}{lc}
\multicolumn{1}{c}{ Indikasi } & $\mathbf{n}$ \\
Dalam persalinan & $49(46,7 \%)$ \\
Ketuban pecah dini & $26(24,8 \%)$ \\
Gawat janin & $10(9,5 \%)$ \\
Perdarahan antepartum & $8(7,6 \%)$ \\
Partus lama & $6(5,7 \%)$ \\
Lainnya & $6(5,7 \%)$ \\
\hline
\end{tabular}

banyak adalah dalam persalinan dan ketuban pecah dini.
Tabel 3. SC Elektif

\begin{tabular}{lc} 
& Indikasi \\
Primigravida & n \\
Riwayat SC & $25(18,7 \%)$ \\
IUGR & $14(10,4 \%)$ \\
Kelainan letak plasenta & $10(7,4 \%)$ \\
Riwayat infertilitas dan obstetri buruk & $8(5,9 \%)$ \\
Bayi >3800 gram & $2(1,49 \%)$ \\
Lainnya & $17(12,61 \%)$ \\
\hline
\end{tabular}

Perbandingan luaran maternal dan neonatal pada kedua kelompok disajikan dalam Tabel 4.

Tabel 4. Analisis bivariat hubungan antara persalinan seksio cesarea dengan luaran maternal dan neonatal

\begin{tabular}{|c|c|c|c|c|c|}
\hline \multirow{2}{*}{ Luaran } & SC Emergensi & SC Elektif & \multirow{2}{*}{$p$} & \multirow{2}{*}{$\mathbf{R R}$} & \multirow{2}{*}{$95 \% \mathrm{Cl}$} \\
\hline & n (\%) & n (\%) & & & \\
\hline \multicolumn{6}{|l|}{ Luaran Maternal } \\
\hline Infeksi & $24(22,9)$ & $9(6,6)$ & 0,000 & 3,43 & $1,68-7,11$ \\
\hline Perdarahan & $10(9,5)$ & $4(2,9)$ & 0,033 & 3,24 & $1,00-9,14$ \\
\hline \multicolumn{6}{|l|}{ Luaran Neonatal } \\
\hline Apgar menit $1<7$ & $43(45,3)$ & $49(36,3)$ & 0,158 & 1,25 & $0,92-1,72$ \\
\hline Apgar menit $5<7$ & $7(7,4)$ & $4(2,9)$ & 0,207 & 2,49 & $0,75-8,32$ \\
\hline Cedera/trauma persalinan & $6(5,7)$ & $3(2,2)$ & 0,183 & 2,57 & $0,66-10,12$ \\
\hline
\end{tabular}


Angka kejadian luaran maternal dan neonatal lebih tinggi terjadi pada seksio cesarea emergensi. Kejadian asfiksia neonatorum dan cedera persalinan lebih tinggi pada seksio cesarea emergensi, namun tidak bermakna secara statistik. Seksio cesarea emergensi secara bermakna berhubungan dengan risiko kejadian infeksi maternal ( $\mathrm{RR} 3,43,95 \% \mathrm{Cl} 1,68-$ $7,11, p=0,000$ ). Dari hasil analisis multivariat dengan menyertakan variabel paritas, usia kehamilan, berat bayi lahir, penyakit hipertensi, dan diabetes melitus sebagai variabel luar, dapat disimpulkan bahwa seksio cesarea emergensi ( $p=0.002, O R 3,65$, 95\% Cl 1.59-8.40) dan usia kehamilan preterm ( $p=0,012$, OR 2,78, 95\% Cl 1,26-6,15) merupakan faktor independent yang meningkatkan risiko terjadinya infeksi maternal. Variabel paritas, berat bayi lahir, penyakit hipertensi, dan diabetes melitus merupakan variabel luar yang berhubungan dengan kejadian infeksi maternal pasca seksio cesarea dengan tingkat kemaknaan $p>0.25$ (tabel 5 dan 6).

Tabel 5. Analisis bivariat hubungan variabel luar dengan kejadian luaran infeksi maternal pasca seksio cesarea pada janin presentasi bokong yang dilakukan seksio cesarea

\begin{tabular}{|c|c|c|c|c|c|c|c|c|}
\hline \multirow{3}{*}{\multicolumn{2}{|c|}{ Variabel Luar }} & \multicolumn{4}{|c|}{ Infeksi } & \multirow{3}{*}{$p$} & \multirow{3}{*}{$\mathbf{R R}$} & \multirow{3}{*}{$95 \% \mathrm{Cl}$} \\
\hline & & \multicolumn{2}{|c|}{ Ya } & \multicolumn{2}{|c|}{ Tidak } & & & \\
\hline & & $n$ & $\%$ & $\mathbf{n}$ & $\%$ & & & \\
\hline \multirow[t]{2}{*}{ Usia ibu } & $<20$ atau $>35$ tahun & 9 & 13,4 & 58 & 86,6 & \multirow[t]{2}{*}{0,942} & \multirow[t]{2}{*}{0,97} & \multirow[t]{2}{*}{$0,48-1,99$} \\
\hline & 20-35 tahun & 24 & 13,8 & 149 & 86,2 & & & \\
\hline \multirow[t]{2}{*}{ Paritas } & Primigravida & 22 & 18,8 & 95 & 81,2 & \multirow[t]{2}{*}{0,025} & \multirow[t]{2}{*}{2,12} & \multirow[t]{2}{*}{$1,08-4,18$} \\
\hline & Multigravida & 11 & 8,9 & 112 & 91,1 & & & \\
\hline \multirow{2}{*}{$\begin{array}{l}\text { Usia } \\
\text { kehamilan }\end{array}$} & $<37$ minggu & 15 & 25,0 & 45 & 75,0 & \multirow[t]{2}{*}{0,003} & \multirow[t]{2}{*}{2,51} & \multirow[t]{2}{*}{$1,35-4,67$} \\
\hline & $\geq 37$ minggu & 18 & 9,9 & 162 & 90,1 & & & \\
\hline \multirow{2}{*}{$\begin{array}{l}\text { Berat bayi } \\
\text { lahir }\end{array}$} & $<2500$ atau $>3500$ gram & 18 & 18,4 & 80 & 81,6 & \multirow[t]{2}{*}{0,081} & \multirow[t]{2}{*}{1,75} & \multirow[t]{2}{*}{$0,93-3,31$} \\
\hline & 2500-3500 gram & 15 & 10,5 & 127 & 89,5 & & & \\
\hline \multirow[t]{2}{*}{ Hipertensi } & Ya & 12 & 20,3 & 47 & 79,7 & \multirow[t]{2}{*}{0,087} & \multirow[t]{2}{*}{1,76} & \multirow[t]{2}{*}{$0,92-3,36$} \\
\hline & Tidak & 21 & 11,5 & 160 & 88,5 & & & \\
\hline \multirow{2}{*}{$\begin{array}{l}\text { Diabetes } \\
\text { mellitus }\end{array}$} & Ya & 2 & 40,0 & 3 & 60,0 & \multirow[t]{2}{*}{0,140} & \multirow[t]{2}{*}{3,05} & \multirow[t]{2}{*}{$0,99-9,36$} \\
\hline & Tidak & 31 & 13,1 & 204 & 86,9 & & & \\
\hline \multirow{2}{*}{$\begin{array}{l}\text { Lama } \\
\text { ketuban } \\
\text { pecah }\end{array}$} & $\geq 8$ jam & 4 & 14,3 & 24 & 85,7 & \multirow[t]{2}{*}{1,000} & \multirow[t]{2}{*}{1,05} & \multirow[t]{2}{*}{$0,39-2,77$} \\
\hline & $<8$ jam & 29 & 13,6 & 183 & 86,4 & & & \\
\hline
\end{tabular}

Tabel 6. Hubungan antara persalinan seksio cesarea dan variabel-variabel luar dengan infeksi maternal dalam analisis multivariat dengan regresi logistik

\begin{tabular}{|c|c|c|c|c|}
\hline & riabel & $p$ & OR & $95 \% \mathrm{Cl}$ \\
\hline Persalinan & $\begin{array}{l}\text { SC emergensi } \\
\text { SC elektif }\end{array}$ & 0,002 & 3,65 & $1,59-8,40$ \\
\hline Usia kehamilan & $\begin{array}{l}>37 \text { minggu } \\
\geq 37 \text { minggu }\end{array}$ & 0,012 & 2,78 & $1,26-6,15$ \\
\hline Paritas & $\begin{array}{l}\text { Primigravida } \\
\text { Multigravida }\end{array}$ & 0,057 & 2,19 & $0,98-6,15$ \\
\hline Berat bayi lahir & $\begin{array}{l}<2500 \text { atau }>3500 \text { gram } \\
2500-3500 \text { gram }\end{array}$ & 1,000 & 0,329 & $1,00-1,001$ \\
\hline Hipertensi & $\begin{array}{l}\text { Ya } \\
\text { Tidak }\end{array}$ & 0,590 & 1,249 & $0,556-2,805$ \\
\hline Diabetes mellitus & $\begin{array}{l}\text { Ya } \\
\text { Tidak }\end{array}$ & 0,458 & 1,998 & $0,322-12,3$ \\
\hline
\end{tabular}


Seksio cesarea emergensi secara bermakna berhubungan dengan risiko kejadian perdarahan (RR 3,24, 95\% Cl 1,00-9,14, p=0,033). Dari hasil analisis multivariat dengan menyertakan variabel seksio cesarea, usia kehamilan, berat bayi lahir, dan diabetes melitus sebagai variabel luar, dapat disimpulkan bahwa seksio cesarea emergensi
( $\mathrm{p}=0.042$, OR 2.27, 95\% Cl 1,06-6,1) dan diabetes melitus ( $p=0,013$, OR 12.42, 95\% Cl 1,68-91,6) merupakan faktor independent yang meningkatkan risiko terjadinya perdarahan. Variabel usia kehamilan dan berat bayi lahir merupakan variabel luar yang berhubungan dengan kejadian perdarahan dengan tingkat kemaknaan $\mathrm{p}>0.25$ (Tabel 7-8).

Tabel 7. Analisis bivariat hubungan variabel luar dengan kejadian luaran perdarahan pada janin presentasi bokong yang dilakukan seksio cesarea

\begin{tabular}{|c|c|c|c|c|c|c|c|c|}
\hline & & & Per & nan & & & & \\
\hline & ariabel Luar & & & & & $p$ & $\mathbf{R} \mathbf{R}$ & $95 \% \mathrm{Cl}$ \\
\hline & & $\mathbf{n}$ & $\%$ & $\mathbf{n}$ & $\%$ & & & \\
\hline Usia ibu & $<20$ atau $>35$ tahun & 3 & 4,5 & 64 & 95,5 & 1,000 & 1,11 & $0,29-4,18$ \\
\hline & 20-35 tahun & 7 & 4,0 & 166 & 96,0 & & & \\
\hline Paritas & Primigravida & 3 & 2,6 & 114 & 97,4 & 0,335 & 0,45 & $0,12-1,72$ \\
\hline & Multigravida & 7 & 5,6 & 116 & 94,4 & & & \\
\hline Usia kehamilan & $<37$ minggu & 5 & 8,3 & 55 & 91,7 & 0,126 & 3,02 & $0,90-10,1$ \\
\hline & $\geq 37$ minggu & 5 & 2,8 & 175 & 97,2 & & & \\
\hline Berat bayi lahir & $<2500$ atau $>3500$ gram & 8 & 8,2 & 90 & 91,8 & 0,017 & 5,84 & $1,27-26,9$ \\
\hline & 2500-3500 gram & 2 & 1,4 & 141 & 98,6 & & & \\
\hline Hipertensi & Ya & 4 & 6,8 & 55 & 93,2 & 0,265 & 2,06 & $0,60-7,04$ \\
\hline & Tidak & 6 & 3,3 & 175 & 96,7 & & & \\
\hline Diabetes & Ya & 2 & 40,0 & 3 & 60,0 & 0,015 & 11,80 & $3,31-42,1$ \\
\hline melitus & Tidak & 8 & 3,4 & 227 & 96,6 & & & \\
\hline Lama ketuban & $\geq 8$ jam & 1 & 3,6 & 27 & 96,4 & 1,000 & 0,85 & $0,11-6,42$ \\
\hline pecah & $<8$ jam & 9 & 4,2 & 203 & 95,8 & & & \\
\hline
\end{tabular}

Tabel 8. Hubungan antara persalinan seksio cesarea dan variabel-variabel luar dengan perdarahan dalam analisis multivariat dengan regresi logistik

\begin{tabular}{|c|c|c|c|c|}
\hline \multicolumn{2}{|c|}{ Variabel } & $P$ & OR & $95 \% \mathrm{Cl}$ \\
\hline Persalinan & $\begin{array}{l}\text { SC emergensi } \\
\text { SC elektif }\end{array}$ & 0,042 & 2,27 & $1,06-6,1$ \\
\hline Diabetes melitus & $\begin{array}{l}\text { Ya } \\
\text { Tidak }\end{array}$ & 0,013 & 12,42 & $1,68-91,6$ \\
\hline Usia kehamilan & $\begin{array}{l}<37 \text { minggu } \\
\geq 37 \text { minggu }\end{array}$ & 0,452 & 1,629 & $0,45-5,805$ \\
\hline Berat bayi lahir & $\begin{array}{l}<2500 \text { atau }>3500 \text { gram } \\
2500-3500 \text { gram }\end{array}$ & 0,305 & 1,89 & $0,559-5,805$ \\
\hline
\end{tabular}

Kehamilan dengan janin presentasi bokong terjadi pada $40 \%$ pada kehamilan 20 minggu, 6-8\% pada kehamilan 34 minggu dan 2-3\% kehamilan aterm. ${ }^{1}$ Angka seksio cesarea terus meningkat di seluruh dunia dan presentasi bokong merupakan $\pm 17 \%$ indikasi utama dikerjakannya seksio cesarea elektif. Seksio cesarea dapat menjadi prosedur untuk menyelamatkan ibu dan bayi, tetapi juga merupakan tindakan yang menyebabkan terjadinya komplikasi jangka pendek dan jangka panjang untuk ibu dan bayi. ${ }^{6}$ Komplikasi maternal dan neonatal lebih tinggi terjadi pada seksio cesarea emergensi daripada seksio cesarea elektif. ${ }^{7.9 .10}$ Infeksi maternal, dehisisensi luka operasi, tromboembolism, operasi ulangan, dan kematian bayi lebih banyak dijumpai pada seksio cesarea emergensi. ${ }^{9}$ 
Dari analisis bivariat, didapatkan risiko kejadian infeksi pasca operasi pada seksio cesarea emergensi 3,43 kali lebih tinggi dibandingkan seksio cesarea elektif. Hal ini sejalan dengan penelitian yang dilakukan oleh Krebs dan Langhoff (2003) yang menyatakan bahwa seksio cesarea elektif memiliki risiko lebih rendah terjadinya infeksi puerperal, infeksi pelvis, dan operasi ulangan karena dehisiensi luka lebih sedikit dibanding seksio cesarea emergensi. ${ }^{11}$ Penelitian yang dilakukan oleh Daniel et al, 2014 juga menyebutkan bahwa risiko terjadinya infeksi pasca seksio cesarea emergensi 4 kali lebih tinggi dibandingkan seksio cesarea elektif. Infeksi yang terjadi termasuk infeksi luka, infeksi saluran kemih dan infeksi saluran pernapasan. ${ }^{12}$ Risiko infeksi diketahui meningkat dengan adanya ketuban pecah dini, diabetes melitus dan hipertensi, ${ }^{13,14}$ namun pada penelitian ini semua variabel tersebut tidak signifikan berpengaruh terhadap kejadian infeksi. Pada analisis multivariat, kejadian infeksi maternal dihubungkan signifikan selain dengan seksio cesarea emergensi, juga dengan usia kehamilan preterm sebagai faktor risikonya. Pasien dengan usia kehamilan preterm meningkatkan 2,78 kali risiko ibu berpeluang mengalami infeksi maternal pasca operasi. Hal ini sejalan dengan penelitian yang dilakukan Hager (2004) bahwa usia kehamilan preterm merupakan salah satu faktor risiko terjadinya komplikasi infeksi pasca seksio cesarea. Hal ini dapat dikarenakan oleh teknik operasi yang lebih sulit karena segmen bawah rahim yang belum berkembang dengan baik. ${ }^{7}$

Pasien dengan seksio cesarea emergensi berisiko mengalami kejadian perdarahan 3,24 kali lebih tinggi dibandingkan seksio cesarea elektif. Hal ini sejalan dengan penelitian yang dilakukan Krebs dan Langhoff (2003) yang menyatakan bahwa seksio cesarea elektif memiliki risiko lebih rendah terjadinya perdarahan dan anemia dibandingkan seksio cesarea emergensi. ${ }^{11}$ Komplikasi yang paling sering terjadi pada seksio cesarea emergensi adalah perdarahan masif. Perdarahan biasanya terjadi karena perluasan robekan segmen bawah rahim, plasenta adherent, dan atonia uteri. Kejadian anemia dan transfusi juga didapatkan 3 kali lebih tinggi pada seksio cesarea emergensi. ${ }^{8,12,15}$ Pada penelitian ini didapatkan, kasus perdarahan yang terjadi pada seksio cesarea elektif adalah 3 pasien dengan kasus atonia uteri dan 1 pasien dengan kasus plasenta akreta. Sembilan pasien $(6,67 \%)$ didiagnosis anemia dan membutuhkan transfusi darah. Kasus perdarahan yang terjadi pada seksio cesarea emergensi, 11 kasus atonia uteri dan 1 kasus robekan segmen bawah rahim yang luas. 16 pasien $(11,9 \%)$ didiagnosis anemia dan membutuhkan transfusi darah. Pada analisis bivariat didapatkan variabel yang mempunyai hubungan dengan angka kejadian perdarahan maternal yaitu berat bayi lahir dan diabetes melitus. Variabel diabetes melitus dan berat bayi lahir dapat menjadi faktor risiko perdarahan, dihubungkan dengan kejadian fetal makrosomia. Namun dibutuhkan penelitian lebih lanjut dikarenakan banyaknya variabel faktor yang tidak diteliti.

Dari skor Apgar menit pertama dan kelima tidak menunjukkan adanya hubungan kejadian skor Apgar rendah dengan seksio cesarea secara statistik, namun tetap bernilai secara klinis. Kejadian asfiksia menit pertama pada seksio cesarea emergensi 1,25 kali lebih tinggi dan kejadian asfiksia menit kelima 2,49 kali lebih tinggi dibandingkan seksio cesarea elektif. Dari penelitian sebelumnya yang dilakukan oleh Krebs, et al, 2003, Cuskon, et al, 2020, dan Diana, et al, 2016 mendapatkan hasil yang berbeda, yaitu skor Apgar bayi yang lahir dengan seksio cesarea elektif lebih baik daripada bayi lahir dengan seksio cesarea emergensi. ${ }^{8,10,11}$ Namun, ini selaras dengan penelitian yang dilakukan oleh Anuwutnavin, et al, 2019 bahwa tidak ada perbedaan hasil skor Apgar menit 1 pada seksio cesarea emergensi dan seksio cesarea elektif. Skor Apgar menit pertama lebih menggambarkan kondisi bayi segera setelah lahir, apakah membutuhkan resusitasi atau tidak dan tidak bisa digunakan untuk memprediksi ada tidaknya luaran neurologis yang buruk di masa depan, sedangkan Apgar menit kelima dapat digunakan untuk prognostik. ${ }^{2,16}$ Pada analisis multivariat, didapatkan usia kehamilan, berat bayi lahir dan hipertensi ibu menjadi faktor risiko paling signifikan yang berhubungan dengan kejadian asfiksia. Pada bayi preterm dengan berat $<2500$ gram, asfiksia dapat terjadi selain karena prematuritas, dapat pula dikarenakan gangguan uteroplasenta karena adanya hipertensi dalam kehamilan, atau pertumbuhan 
janin terhambat. Sedangkan pada bayi dengan berat badan >3500 gram, kejadian asfiksia kemungkinan akibat gangguan aliran uteroplasenta dikarenakan postmaturitas. $^{2}$

Cedera persalinan pada seksio cesarea emergensi $(5,7 \%)$ lebih banyak daripada seksio cesarea elektif $(2,2 \%)$, namun didapatkan nilai $p=1.083(p>0.05)$, sehingga hanya bermakna secara klinis, namun tidak bermakna signifikan secara statistik antara metode seksio cesarea dengan kejadian cedera persalinan pada bayi. Hasil penelitian ini sama dengan penelitian yang dilakukan oleh Anuwutnavin, et al, 2019 bahwa tidak didapatkan trauma persalinan pada bayi yang dilahirkan dengan seksio sesarea, baik emergensi maupun elektif. Namun berbeda dengan Krebs, et al, 2003, dan Daniel, et al, 2014 yang melaporkan bahwa seksio cesarea emergensi berhubungan dengan risiko lebih tingginya kejadian nilai Apgar rendah, cedera persalinan, dan morbiditas neonatal. Walaupun seksio cesarea dapat menurunkan risiko terjadinya cedera persalinan pada neonatal dibandingkan persalinan vaginal, namun tidak mengeliminasi kemungkinan terjadinya cedera. Variabel yang berpengaruh terhadap cedera neonatal adalah usia kehamilan $(p<0,05)$, dimana bayi prematur lebih rentan mengalami cedera dibandingkan bayi aterm. Cedera yang terjadi pada penelitian ini antara lain fraktur klavikula, fraktur femur, laserasi kulit, cephal hematoma.

\section{KESIMPULAN}

Seksio cesarea emergensi secara signifikan berhubungan dengan luaran buruk maternal, yaitu terjadinya komplikasi infeksi dan perdarahan, namun tidak memberikan luaran neonatal yang lebih buruk dibandingkan seksio cesarea elektif. Pemeriksaan antenatal dan pengambilan keputusan penatalaksanaan yang tepat diperlukan untuk mencegah terjadinya luaran maternal dan neonatal yang buruk.

\section{DAFTAR PUSTAKA}

1. Cunningham, FG., Leveno, KJ., Bloom, SJ., Spong, CY., Dashe, JS., Hoffman, BL., Casey, BL., Sheffield, JS. 2014. William Osbstetric. $24^{\text {st }}$. New York: McGrawHill.
2. Arias, F. 2015. Practical guide to high-risk pregnancy and delivery: A South Asian Perspective. Elsevier. Fourth Edition.

3. Hannah, M., Hannah, W., Hewson, S., Hodnett, E., Saigal, S., Willan, A. 2000. Planned caesarean section versus planned vaginal birth for breech presentation at term: a randomised multicentre trial. Term Breech Trial Collaborative Group Lancet 356: pp 1375-1383.

4. Burgos, J., Rodríguez, L., Cobos, P., Osuna, C., Centeno, M del Mar., Larrieta, R., Astorquiza, T Martínez., Llebrez, Fernández. 2015. Management of breech presentation at term: a retrospective cohort study of 10 years of experience. Journal of Perinatology, pp 1-6

5. Azria, Elie., Meaux, Jean-Patrick Le., Khoshnood, Babak., Alexander, Sophie., Subtil, Damien., Goffinet, François. 2012. Factors associated with adverse perinatal outcomes for term breech fetuses with planned vaginal delivery. American Journal Obstetrics and Gynecology; 207:285.e1-9.

6. Macharey, G. 2018. Breech Presentation and Delivery in Singleton Term Pregnancy in Finland. Department of Obstetrics and Gynecology, Helsinki University Hospital and University of Helsinki. Helsinki.

7. Hager, R.M.E., Daltveit, A.K., Hofos, D., Nilsen, T.S., Kolaas, T., et al. Complication of cesarean deliveries: Rates and risk factors. American Journal of Obstetrics and Gynecology. 190. pp 428-434. doi: 10.1016/j. ajog.2003.08.037

8. Diana, V., Tipandjan, A. 2016. Emergency and elective caesarean sections: comparison of maternal and fetal outcomes in a suburban tertiary care hospital in Puducherry. International Journal of Reproduction, Contraception, Obstetrics and Gynecology, volume 5(9), pp 3060-3065.

9. Yang, X.J., Sun, S.S. 2017. Comparison of maternal and fetal complication in elective and emergency cesarean section: a systematic review and metaanalysis. Archives of Gynecology and Obstetrics. Springer Berlin Heidelberg. 296(3). pp. 503-512. doi: 10.1007/s00404-017-4445-2.

10. Coskun, B., Pay, R.E., Coskun, B., 2020. Comparison of Emergency and Elective Cesarean Sections in the Breech Presentation: A Case-Control Study. Medical Journal of Bakirkoy.16(2), pp.132-7.

11. Krebs, L., Langhoff, J., 2003. Elective cesarean delivery for term breech. Obstetrics and Gynecology Journal; 101(4): pp 690-696.

12. Daniel, S., Viswanathan M., Simi B., Nazeema A., 2014, Study of Maternal Outcome of Emergency and Elective in A Semi-Rural Tertiary Hospital. National Journal of Medical Research, Volume 4(1), pp 14-18.

13. Krieger, Y., Walfisch, A. \& Sheiner, E., 2016. Surgical site infection following cesarean deliveries: trends 
and risk factors. The Journal of Maternal-Fetal \& Neonatal Medicine, 7058, pp.1-5.

14. Schneid-Kofman, N., Sheiner, E., Levy, A., Holcberg, G., 2005. Risk factors for wound infection following cesarean deliveries. International Journal of Gynecology and Obstetrics, 90, pp.10-15.

15. Ghazi, A., Karim, F., Husain, A.M., et al. 2012. Maternal morbidity in emergency versus elective cesarean section at tertiary care hospital. Journal of Ayub Medical College. 24(1). pp 10-13.
16. Anuwutnavin, S., Kitnithee, B., Chanprapaph, P., et al. 2019. Comparison of maternal and perinatal morbidity between elective and emergency caesarean section in singleton-term breech presentation. Journal of Obstetrics and Gynaecology; 40: pp 1-7. doi:10.1080/01443615.2019.1634018 